\title{
Mesenchymal stem cells decrease lung inflammation during sepsis, acting through inhibition of the MAPK pathway
}

Leonardo Pedrazza ${ }^{1^{*}}$ DD, Monica Cubillos-Rojas ${ }^{2}$, Fernanda Cristina de Mesquita ${ }^{1}$, Carolina Luft ${ }^{3}$, Aline Andrea Cunha ${ }^{3}$, Jose Luis Rosa ${ }^{2}$ and Jarbas Rodrigues de Oliveira ${ }^{1}$

\begin{abstract}
Background: Sepsis is a severe medical condition that ranks among the top 10 causes of death worldwide and which has permanently high incidence rates. Mesenchymal stem cells (MSCs) have been found to be potent modulators of immune responses. More importantly, there is evidence that MSCs have a beneficial effect on preclinical models of polymicrobial sepsis. However, the changes caused by the MSCs in the effector cells of the host immune system remain unclear.

Methods: A mouse model of sepsis (male C57BL/6 mice) with three experimental groups was used for experiments in vivo: a control group, an untreated septic group, and a septic group treated with MSCs. In vitro experiments were performed using a cell line of pulmonary macrophages (RAW 264.7) co-cultured with MSCs and stimulated with lipopolysaccharide (LPS).

Results: In vivo we demonstrated that treatment with MSCs was able to reduce the expression of cyclooxygenase-2 (COX-2) and nuclear factor kappa B (NF-kB), and thereby decrease the production of inflammatory cytokines. In vitro experiments using a co-culture of macrophages with MSCs showed a decrease in COX-2 and NF-KB, and showed that this reduction was directly related to the ability of MSCs to inhibit phosphorylation of ERK, RSK, and p38, enzymes that belong to the family of mitogen-activated protein kinases (MAPKs).

Conclusions: This study demonstrated that MSCs are able to inhibit the MAPK pathway activation, modulating the inflammatory response during sepsis. This understanding that MSCs can remodel the response of host cells and improve the course of sepsis is essential for developing new treatments for this pathology.
\end{abstract}

Keywords: Sepsis, Mitogen-activated protein kinases, Mesenchymal stem cells, Macrophages

\section{Background}

Sepsis is a severe medical condition that ranks among the top 10 causes of death worldwide and which has permanently high incidence rates [1]. Even with appropriate antibiotic and resuscitative therapies, sepsis carries a 30\% mortality rate and significant morbidity associated with organ failure [2]. Furthermore, it incurs a staggering $\$ 16.7$ billion cost in the US health economy, with over 750,000 annual cases and greater than 200,000 deaths each year [3].

\footnotetext{
* Correspondence: leopedrazza@gmail.com

${ }^{1}$ Laboratório de Pesquisa em Biofísica Celular e Inflamação, Pontifícia Universidade Católica do Rio Grande do Sul (PUCRS), Porto Alegre, Rio Grande do Sul CEP 90619-900, Brazil

Full list of author information is available at the end of the article
}

Sepsis is caused by an infection and involves a complex interaction between the pathogen and the host immune cells, characterized by a systemic inflammatory state [4]. Moreover, the role of the immune response is crucial to fight infection; it is also responsible for the inflammatory tissue infiltration and severe organ damage, both hallmarks of sepsis [5]. Evidence suggests that modulation of pro- and anti-inflammatory factors contributes to the suppression of immune effector cells, induces the systemic inflammation, and causes tissue damage during the sepsis [6].

Over the last few years, many studies have been conducted in order to decrease the mortality rate associated with sepsis, but the pharmaceutical research community 
is not getting any substantial new messages regarding drug design, development, and therapy [7]. However, as experimental studies have demonstrated in the setting of sepsis syndrome, mesenchymal stem cell (MSC) treatment notably alleviated the sepsis-induced inflammatory reaction, decreased mortality, and improved prognostic outcome [8-12].

MSCs are a subpopulation of multipotent cells that may be isolated from various adult tissues and organs. Several studies have described MSCs as a novel therapeutic strategy for the treatment of diseases related to inflammation and tissue injury because they are potent modulators of immune system, with the ability to regulate both the innate and adaptive immune response [13, 14]. Several studies demonstrate that the protective role of MSCs in sepsis may be attributed to the soluble paracrine factors released by these cells, such as interleukin (IL)-10, prostaglandin E2 (PGE2), tumor necrosis factor (TNF) $-\alpha$ and IL-6 [15-17].

Previous studies in experimental model of sepsis demonstrated the ability of MSCs to reprogram macrophages from a pro-inflammatory state to an anti-inflammatory state through the release of PGE2, causing increased secretion of IL-10. Nevertheless, the pathways that are altered in this reprogramming of effector cells of the immune system are unclear [18].

We know that the cyclooxygenase-2 (COX-2) is responsible for the production of a huge amount of PGE2, which is highly expressed during the inflammatory process [19]. The pathway that usually regulates COX-2 expression in inflammation involves a family of highly conserved intracellular signaling molecules, the mitogen-activated protein kinases (MAPKs) [20]. The MAPK pathway has been implicated in processes regulating cell growth, differentiation, apoptosis, and inflammation. In mammals, there are three MAPK subgroups, the extracellular signal-regulated kinase (ERK), c-JUN $\mathrm{N}$-terminal kinases (JNK) and p38 [21].

Therefore, in this study we investigated the ability of MSCs to decrease COX-2 production and other inflammatory mediators through inhibition of the MAPK pathway. For this purpose we used a model of sepsis previously developed by our laboratory, consisting of the introduction of a sterile gelatin capsule in the peritoneal cavity containing Escherichia coli suspension and nonsterile fecal content, subsequently followed by an in vitro investigation using a cell line of lung macrophages, which are important effector cells of the immune system involved in many immunological reactions.

\section{Methods}

Animals

Male C57BL/6 mice (8-12 weeks old) were kept on shelves in ventilated cages that provide 60 air cycles per hour, with relative humidity ranging between 55 and
$65 \%$, a 12-h light-dark cycle, a temperature of $22 \pm 2{ }^{\circ} \mathrm{C}$, and free access to food and water. The animals were maintained in accordance with the Guiding Principles in the Care and Use of Animals approved by the Council of the American Physiological Society. The experimental protocol was approved by the Ethics Research Committee of Pontifícia Universidade Católica do Rio Grande do Sul (protocol number 14/00403).

\section{MSC culture and characterization}

Male C57BL/6 mice (8-12 weeks old) were MSC donors. Under sterile conditions, the animals were anesthetized (pentobarbital $50 \mathrm{mg} / \mathrm{kg}$ intraperitoneally) and, after the collection of the adipose tissue, mice were killed by cervical dislocation. In humans, adipose tissue is usually collected by needle biopsy or liposuction aspiration; for this reason, we chose to perform the collection of adipose tissue from anesthetized animals and proceed to euthanasia later. This step makes the work closer to what happens in the clinic. Adipose tissue was obtained from the epididymal adipose tissue, cut into small pieces, collagenase digested, filtered, and then cultured using Dulbecco's modified Eagle's medium (DMEM; Invitrogen Corporation, CA, USA) without ribonucleosides or deoxyribonucleosides containing $2 \mathrm{mML}$-glutamine and $20 \%$ fetal bovine serum (FBS; Invitrogen, Carlsbad, USA), with $1 \%$ penicillin-streptomycin. Cells were passaged every 3-4 days by trypsinization when they reached $70-80 \%$ confluence and were used for the experiments between passages 3 and 4 . Between each passage, cell viability was measured using the trypan blue exclusion test. MSCs were cultured in a humidified incubator at $5 \% \mathrm{CO}_{2}$ and $37{ }^{\circ} \mathrm{C}$ under sterile conditions. Before each experiment, cells were trypsinized, counted, washed twice with phosphate-buffered saline (PBS) and resuspended in PBS. MSCs were characterized by expression of the cellular markers $\left(\mathrm{CD} 0^{+}, \mathrm{CD} 105^{+}\right.$, $\mathrm{CD} 34^{-}$, and $\mathrm{CD}^{-} 5^{-}$), determined by flow cytometry analysis (Bio-Rad, Hercules, USA). MSCs were induced to differentiate into adipocytes, osteocytes, and chondrocytes using cell differentiation kits from R\&D Systems (Minneapolis, MN, USA) in accordance with the recommendations of the manufacturer.

\section{Experimental sepsis induction and treatment}

The animals were weighed and then anesthetized with a mixture of ketamine $(80 \mathrm{mg} / \mathrm{kg})$ and xylazine $(20 \mathrm{mg} / \mathrm{kg})$ intraperitoneally. The abdomen of each animal was shaved and cleaned with povidone-iodine solution. A 1$\mathrm{cm}$ midline abdominal incision was made to expose the linea alba. The peritoneum was opened by blunt dissection. Sepsis was induced by introducing a sterile gelatin capsule size " 1 " in the peritoneal cavity containing another sterile capsule size "2" with the Escherichia coli 
(3 $\mu \mathrm{L}$; ATCC 25922) suspension and non-sterile fecal content $(20 \mathrm{mg})$. This experimental model was developed by our laboratory $[11,22]$. The animals were then divided into three groups: 1 ) sham (mice were implanted with an empty capsule and received a retro-orbital injection of $100 \mu \mathrm{L}$ PBS); 2) sepsis (sepsis-induced and received a retro-orbital injection of $100 \mu \mathrm{L} \mathrm{PBS}$ ); and 3) sepsis + MSCs (sepsis-induced and treated with $1 \times 10^{6}$ MSCs in a retro-orbital injection of $100 \mu \mathrm{L}$ PBS at the time of induction). We also used another model of sepsis induced by the injection of lipopolysaccharide (LPS) from E. coli 026:B6 (12.5 mg/kg; Sigma-Aldrich, St. Louis, USA) intraperitoneally. The animals were divided into the same groups as in the other model. Blood samples were collected using cardiac puncture $12 \mathrm{~h}$ after sepsis induction. This time was determined from previous studies in our laboratory.

\section{Histological analysis}

The superior lobe of the right lung was ligated and prepared for histological and morphological analysis. Lungs were perfused with $10 \%$ buffered formalin on a gravity column $(20 \mathrm{mmHg})$. Tissue specimens were embedded in paraffin blocks, cut into 4- $\mu \mathrm{m}$ sections, stained with hematoxylin and eosin ( $\mathrm{H} \& \mathrm{E})$, and examined by light microscopy. Other sections were sequentially subjected to immunostaining analysis. After deparaffinization, the sections were sequentially treated with $1 \% \mathrm{H}_{2} \mathrm{O}_{2}$ for $10 \mathrm{~min}$ and rinsed thoroughly with PBS. Sections were blocked with $2 \%$ normal blocking serum in PBS at room temperature for $60 \mathrm{~min}$ to suppress any nonspecific binding of IgG, followed by incubation with anti-COX2 (dilution 1:200; Merck Millipore, Darmstadt, GER), or nuclear factor kappa B (NF-кB) p65 (dilution 1:200; Cell signaling, Danvers, USA). The cellular nuclei were stained using $\mathrm{TO}-\mathrm{PRO}^{\circ} 3$ (dilution 1:1000; Thermo Fisher Scientific, Waltham, USA). All of the slides were evaluated by confocal immunofluorescence microscopy. We calculated the inflammatory lung tissue score using the software Image-Pro Plus (Medical Cybernetics). The score for peribronchial and perivascular inflammation was evaluated on a subjective scale of $0-3$, as described elsewhere [23]. A value of 0 was assigned when no inflammation was detectable, a value of 1 was adjudged for occasional cuffing with inflammatory cells, a value of 2 when most bronchi or vessels were surrounded by a thin layer (one to five cells thick) of inflammatory cells, and a value of 3 was given when most bronchi or vessels were surrounded by a thick layer (more than five cells thick) of inflammatory cells.

\section{Cytokine quantification}

To determine cytokine levels, serum samples were collected from mice $12 \mathrm{~h}$ after sepsis induction. Multiple soluble cytokines (IL-6, TNF- $\alpha$, IL-10) were simultaneously measured using a Luminex Multiplex Assay kit (Thermo Fisher Scientific). We used a luminometer Luminex ${ }^{\circ}$ 100/200 (Luminex Corporation, Austin, USA) and the results were analyzed using the software xPO$\mathrm{NENT}^{\circ}$ Solutions software (Luminex Corporation).

\section{Macrophage stimulation and macrophage-mesenchymal stem cell co-culture experiments}

The RAW 264.7 macrophage cell line was obtained from Sigma-Aldrich (USA) and grown to confluence in DMEM containing L-glutamine $(2 \mathrm{mM})$, penicillin $(100 \mathrm{IU} / \mathrm{mL})$, streptomycin $(100 \mathrm{mg} / \mathrm{mL})$, and $10 \% \mathrm{FBS}$ at $37^{\circ} \mathrm{C}$ in a $5 \%$ $\mathrm{CO}_{2}$ humidified incubator. Macrophages were plated in six-well plates at a concentration of $3 \times 10^{5}$ cells in $2 \mathrm{~mL}$ per well. After this, MSCs were also co-cultured in a proportion 1:10 with the macrophages in the same well. After $24 \mathrm{~h}$, macrophages and macrophages co-cultured with MSCs were stimulated with LPS from $E$. coli 026:B6 $(1 \mu \mathrm{g} / \mathrm{mL}$; Sigma-Aldrich) at different times.

\section{Western blot analysis}

Macrophages or lung tissue were lysed in CHAPS lysis buffer $(10 \mathrm{mM}$ Tris-HCl, pH 7.5, $100 \mathrm{mM} \mathrm{NaCl}, 0.3 \%$ CHAPS, $50 \mathrm{mM} \mathrm{NaF}, 1 \mathrm{mM}$ sodium vanadate, $1 \mathrm{mM}$ phenylmethylsulfonyl fluoride, $5 \mu \mathrm{g} / \mathrm{mL}$ leupeptin, $5 \mu \mathrm{g} / \mathrm{mL}$ aprotinin, $1 \mu \mathrm{g} / \mathrm{mL}$ pepstatin A, $50 \mathrm{mM} \beta$ - glycerophosphate, $100 \mu \mathrm{g} / \mathrm{mL}$ benzamidine) for $30 \mathrm{~min}$ at $4{ }^{\circ} \mathrm{C}$ and equal amounts of proteins were separated by electrophoresis. We used Tris-Acetate PAGE systems as previously described $[24,25]$. After running the gel, the proteins were transferred to PVDF membranes and viewed by immunoblotting, as described elsewhere [23, 24]. Band intensities were analyzed with a gel documentation system (LAS-3000 Fujifilm). The levels of phosphorylated proteins (p-p38, pERK1/2, and pRSK) were standardized with relative levels of their total amount. COX-2 and NF-kB were standardized with respect to GAPDH levels and all was expressed as a percentage of controls. We used the following antibodies for the experiments: anti-COX-2 (1:1000 dilution; Merck Millipore, Darmstadt, GER), NF-кB p65 (1:1000 dilution), phospho-ERK1/2 (1:1000 dilution), phospho-p38 (1:1000 dilution), phospho-RSK (1:1000 dilution; Cell signaling, Danvers, EUA), total ERK1/2 (1:1000 dilution; Aviva Systems Biology, San Diego, USA), p38 (1:1000 dilution; Santa Cruz Biotechnology, Santa Cruz, USA), RSK (1:1000 dilution; Cell Signaling Technology), and anti-GAPDH (1:3000 dilution; Sigma-Aldrich).

\section{Quantitative real-time polymerase chain reaction (PCR) analysis}

Macrophages were prepared and subjected to RNA isolation using TRIsure Reagent (Bioline), followed by reverse transcription to cDNA. cDNA was synthesized 
using a cDNA reverse transcription kit. Quantitative PCR amplification reactions were performed with TaqMan ${ }^{\circ}$ PCR Master Mix (Invitrogen Life Technologies, Massachusetts, USA) according to the manufacturer's instructions. Quantitative PCR amplification reactions were performed in the 7500 Fast Real-Time PCR System (Applied Biosystems). The following pre-designed TaqMan assays were used: GAPDH (Mm99999915_g1), IL$1 \beta$ (Mm00434228_m1), IL-6 (Mm00446190_m1), IL-10 (Mm00439616_m1), and COX-2 (Mm00478377_g1). Values were normalized to GAPDH expression.

\section{Cell culture and transfection}

The mouse COX-2 promoter-luciferase construct pCOX511, NF-kB promoter-luciferase construct pNFKB-Luc ${ }^{+}$ (Stratagene), and pSV40- $\beta$-galactosidase control vector (Promega) were generous gifts from Dr. Francesc Ventura (Universitat de Barcelona). Cells were transfected using Lipofectamine LTX (Invitrogen), and after $6 \mathrm{~h}$ the treated group was co-cultivated with MSCs. The next day, cells were serum starved before reaching confluence and treated with LPS $(1 \mu \mathrm{g} / \mathrm{mL}$; Sigma-Aldrich) for 24 and $48 \mathrm{~h}$. Luciferase activities were quantified using the luciferase assay system (Promega, Madison, WI, USA). Luciferase values were normalized using $\beta$-galactosidase, and activity measured with the Luminescent $\beta$-Galactosidase Detection Kit II (CLONTECH, Palo Alto, CA, USA).

\section{Statistical analysis}

The data were analyzed by one-way analysis of variance (ANOVA) or Student's $t$ test. For comparison of significance, Tukey's test was used as a post-hoc test according to the statistical program GraphPad Prism. Quantitative data are presented as means \pm SEM. Differences were considered significant at $p<0.05$.

\section{Results}

MSC administration ameliorates inflammation on sepsis in the lung

As a first step, we used two models of sepsis induction in mice to verify the ability of MSCs to decrease pulmonary inflammation. When we performed H\&E staining $12 \mathrm{~h}$ after sepsis induction, it was observed that induction using only LPS was not able to cause inflammation in the lung. In contrast, sepsis induction performed with the capsule model, previously standardized by our laboratory, was able to cause an increase in lung cell infiltrates (Fig. 1a).

We calculated the score for inflammatory lung tissue using the software Image-Pro Plus (Medical Cybernetics). It was possible to evaluate in the septic group that there was an increase in the inflammatory score, both peribronchial and perivascular, when compared with the sham group. The MSC-treated group had a reduced score when compared with the septic group, demonstrating the ability of MSCs to decrease inflammation in the lung tissue (Fig. 1b).

In previous studies from our laboratory, using this same model, we observed a decreased production of inflammatory cytokines [11]. In the present study, we measured the concentration of two inflammatory markers, IL-6 and TNF- $\alpha$, and one anti-inflammatory marker, IL-10, in

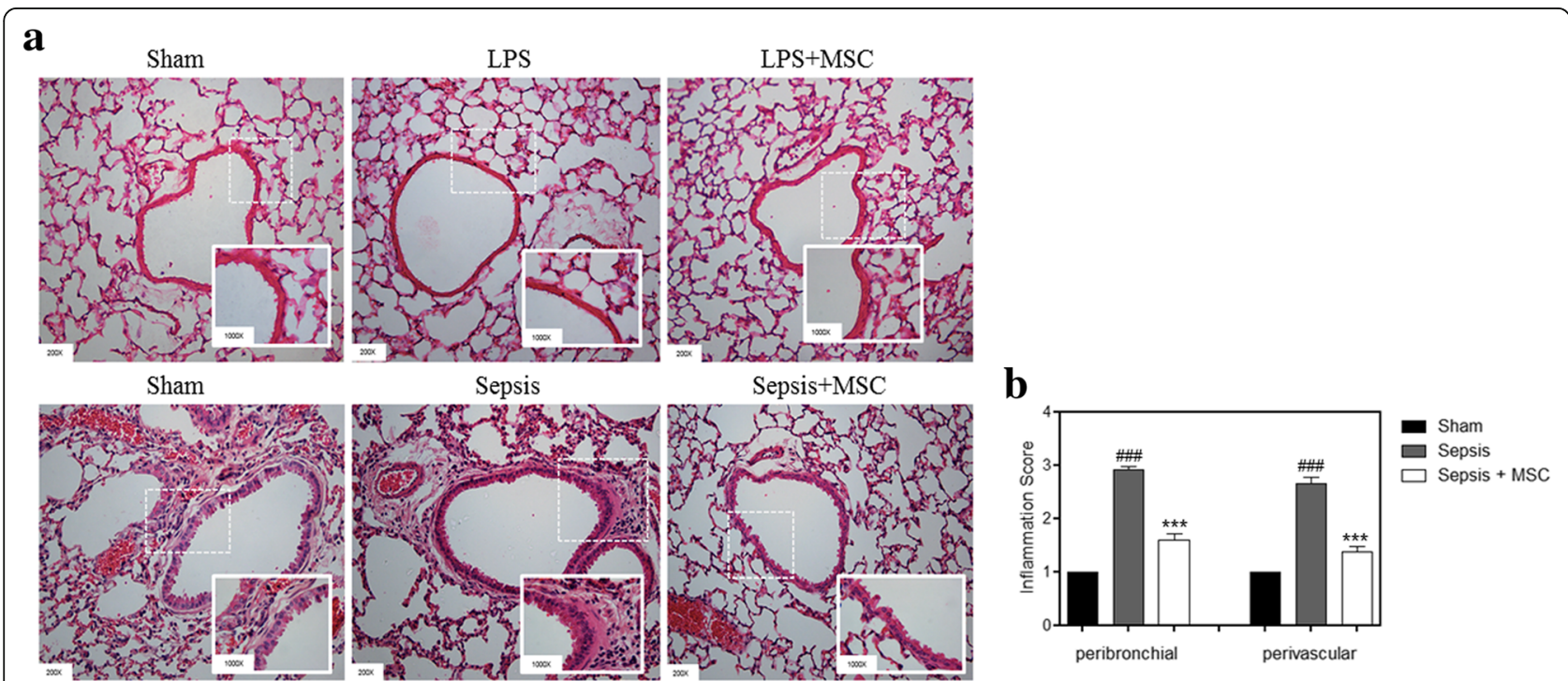

Fig. 1 Mice treated with MSCs showed a reduced inflammation score in the lung. a Lung sections were subjected to H\&E staining. $\mathbf{b}$ The inflammatory cells that infiltrated into the peribronchial and perivascular lung tissues in the sepsis group were ameliorated after MSC administration ( $\times 200$ magnification). Data represent the mean \pm SEM,$n=5$. \#\#\# $p<0.001$, sham versus sepsis group; ${ }^{* * *} p<0.001$, sepsis versus sepsis + MSC group. LPS lipopolysaccharide; MSC mesenchymal stem cell 

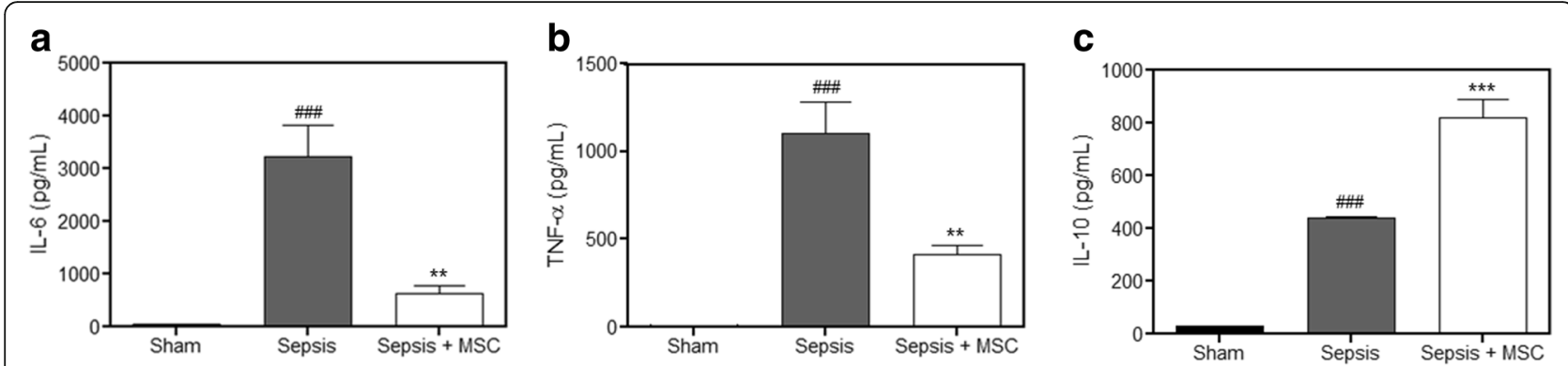

Fig. 2 Mice treated with MSCs show reduced inflammatory markers. The pro-inflammatory factors tumor necrosis factor-alpha (TNF-a) and interleukin-6 (IL-6), and the anti-inflammatory factor IL-10 in the serum were detected by luminescence. The serum showed a significant increase in IL-6 (a) and TNF-a (b) in the sepsis group compared with the levels in the sham group. A significant decrease in TNF-a and IL-6 was observed in the sepsis + mesenchymal stem cell (MSC) group compared with the levels in the sepsis group. Furthermore, the serum showed a significant increase in IL-10 (c) in the sepsis group compared with the levels in the sham group, and a greater increase in the sepsis + MSC group when compared with the septic group. Data represent the mean \pm SEM, $n=10 .{ }^{\# \#} p<0.001$, versus sham group; ${ }^{* *} p<0.01$, ${ }^{* *} p<0.001$, versus sepsis group

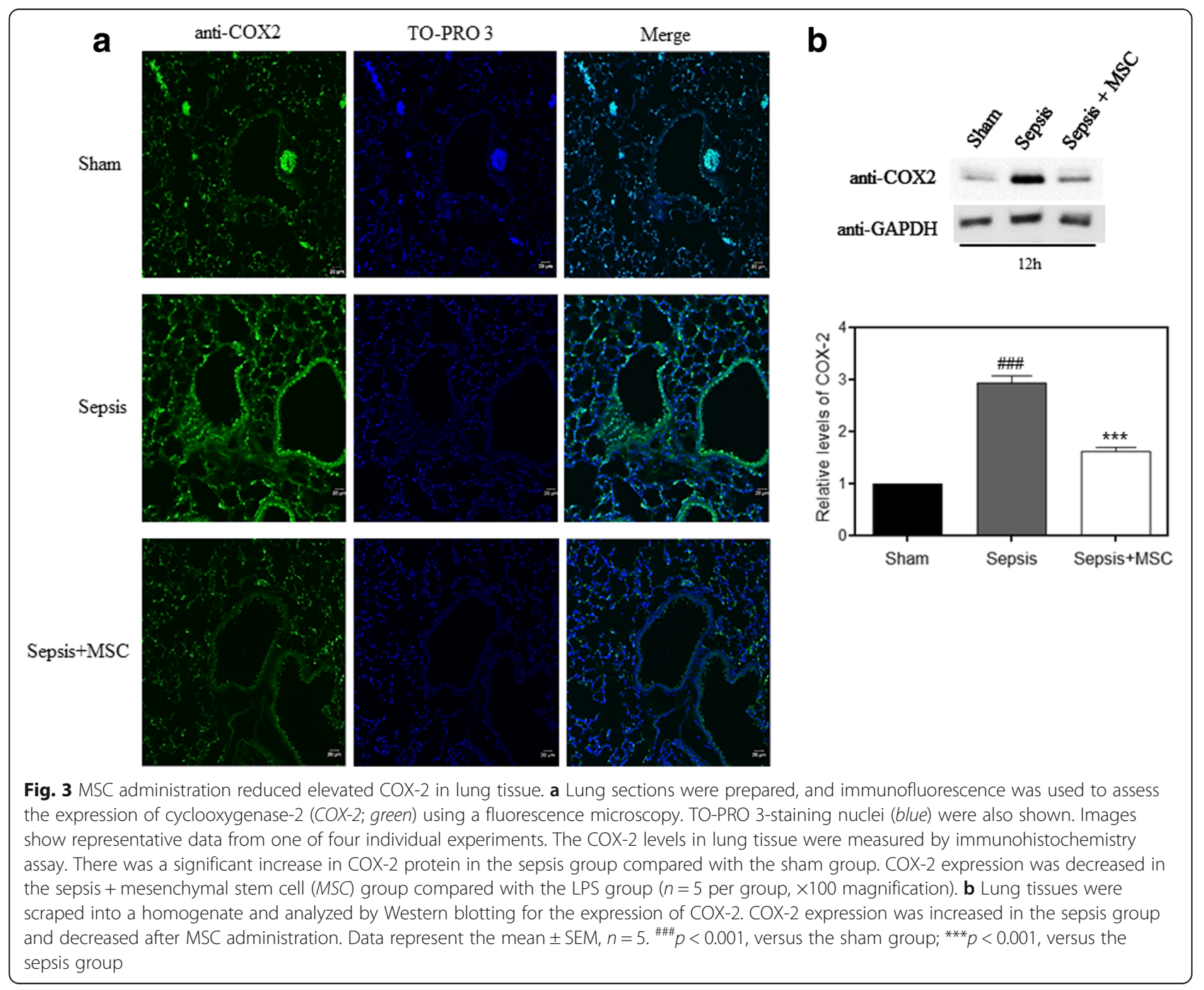


serum. IL- 6 and TNF- $\alpha$ were significantly increased in the sepsis group compared with the sham group, and this increase was reduced in the sepsis group treated with MSCs (Fig. 2a and b). Furthermore, the group that received MSCs had a greater increase in IL-10 than the untreated sepsis group (Fig. 2c). These results demonstrate the anti-inflammatory potential of these cells.

\section{MSCs attenuate COX-2 and NF-KB expression in lung tissue}

COX-2 is overexpressed in response to inflammatory inducers and this increase is responsible for the production of various factors involved in the inflammatory process [26]. Thus, we investigated whether MSCs during sepsis were able to decrease the expression of COX-2 in lung tissue. First, we performed immunofluorescence staining and made a comparison between the groups. We saw an increase in the sepsis group compared with the control group. However, this increase was not observed in the sepsis group that received treatment with MSCs (Fig. 3a). To confirm that COX-2 expression was really reduced in the group treated with MSCs, we performed a Western blot and again observed a decrease in the treated group when compared with the untreated sepsis group (Fig. 3b).

We also investigated if there was a reduction in the expression of NF- $\mathrm{kB}$, which is a transcriptional regulator and induces the expression of several genes including COX-2. When we performed immunofluorescence staining, we observed that the sepsis group had increased $\mathrm{NF}-\kappa \mathrm{B}$ compared with the control group, and that this increase was reduced on treatment with MSCs (Fig. 4a). We also conducted Western blotting to confirm this decrease. The increase in NF- $\mathrm{kB}$ expression in the MSCtreated group is significantly reduced when compared to the sepsis group (Fig. 4b).

\section{LPS-induced pERK, pRSK, p-p38, and NF-KB upregulation} in the macrophage cell lines

Macrophages are directly involved in inflammation and are responsible for the release of several cytokines and

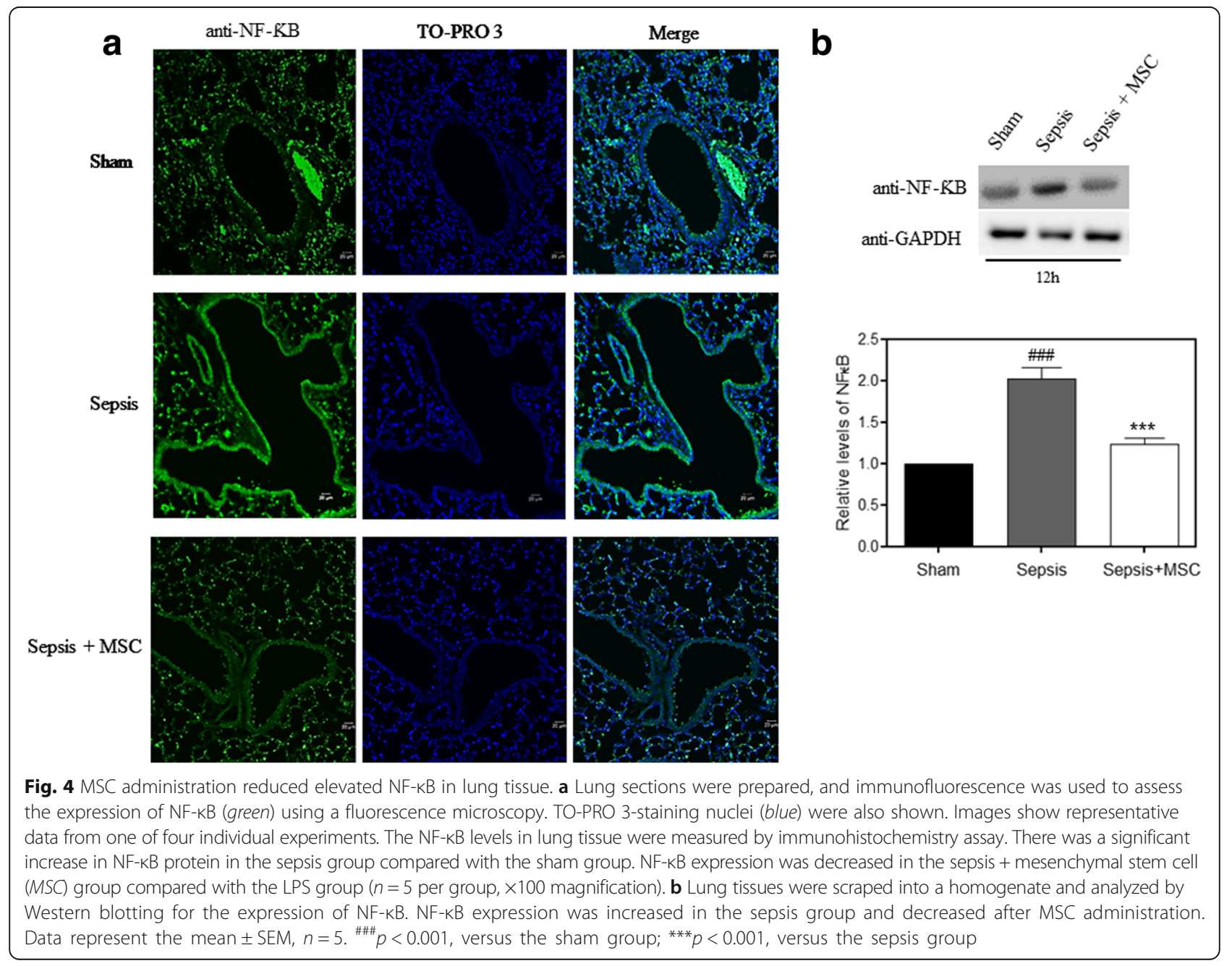


increased COX-2 expression [27]. To investigate the possible mechanism by which MSCs can reduce lung inflammation during sepsis, we performed in vitro experiments using a cell line of pulmonary macrophages (RAW 264.7) stimulated with LPS. We know that the principal route of activation of COX-2 production and other inflammatory cytokines such as TNF- $\alpha$ and IL-1 occurs via the MAPK pathways, so we attempted to verify that this could be a potential mechanism of action of the MSCs.

First, we performed a time-course experiment to evaluate the best activation times of these proteins by Western blot. We tested the phosphorylation of p38, ERK1/2, and RSK, which is a substrate of ERK, and the NFKB expression. The best activation times were concentrated between $5 \mathrm{~min}$ and $24 \mathrm{~h}$, so we chose three times-15, 30, and $60 \mathrm{~min}-$ for the following experiments (Fig. 5).

\section{LPS-induced pERK, pRSK, p-p38, and NF-kB expression is reduced in macrophages co-cultured with MSCs}

To investigate if the MSCs were able to reduce the activation induced by LPS, we co-cultivated macrophages with MSCs. Macrophages were co-cultured for $24 \mathrm{~h}$ with the MSCs and, afterwards, were treated with LPS according to the predefined times. NF- $\mathrm{kB}$ and p-RSK were reduced in the RAW + MSC group when compared with the group exposed to LPS without co-cultivation at all times (Fig. 6a and d). Macrophages co-cultured with
MSCs had decreased phosphorylation of p-p38 and pERK at 15 and 30 min compared to the RAW group stimulated with LPS (Fig. 6b and c).

We included a group with only stem cells (without coculture with macrophages) to demonstrate that there is no influence or background expression from the MSCs, and the results show that the expression of proteins studied comes only from macrophages (Fig. 7). We performed these Western blot experiments using proportionally $10 \%$ of the amount of protein used in the cocultivated group, since in the RAW + MSC group the cells are plated proportionally at 10:1.

To confirm our findings by Western blot, we performed immunofluorescence staining in all groups for p-p38, pERK1/2, p-RSK, and NF-kB. Our results showed the same profile found from the Western blot. It was shown that co-cultivation with MSCs inhibited NF- $\mathrm{kB}$ expression and the phosphorylation of p-38, ERK1/2, and RSK when compared with the group that had only induction with LPS. All these results demonstrate the ability of these cells to prevent the activation of the MAPK pathway that is essential for inflammation (Fig. 8).

\section{Macrophage cell lines co-cultured with MSCs prevent LPS-} induced COX-2 and NF-kB expression over the long-term We wanted to know if the inhibition of phosphorylation in the MAPK pathways caused by MSCs could affect the

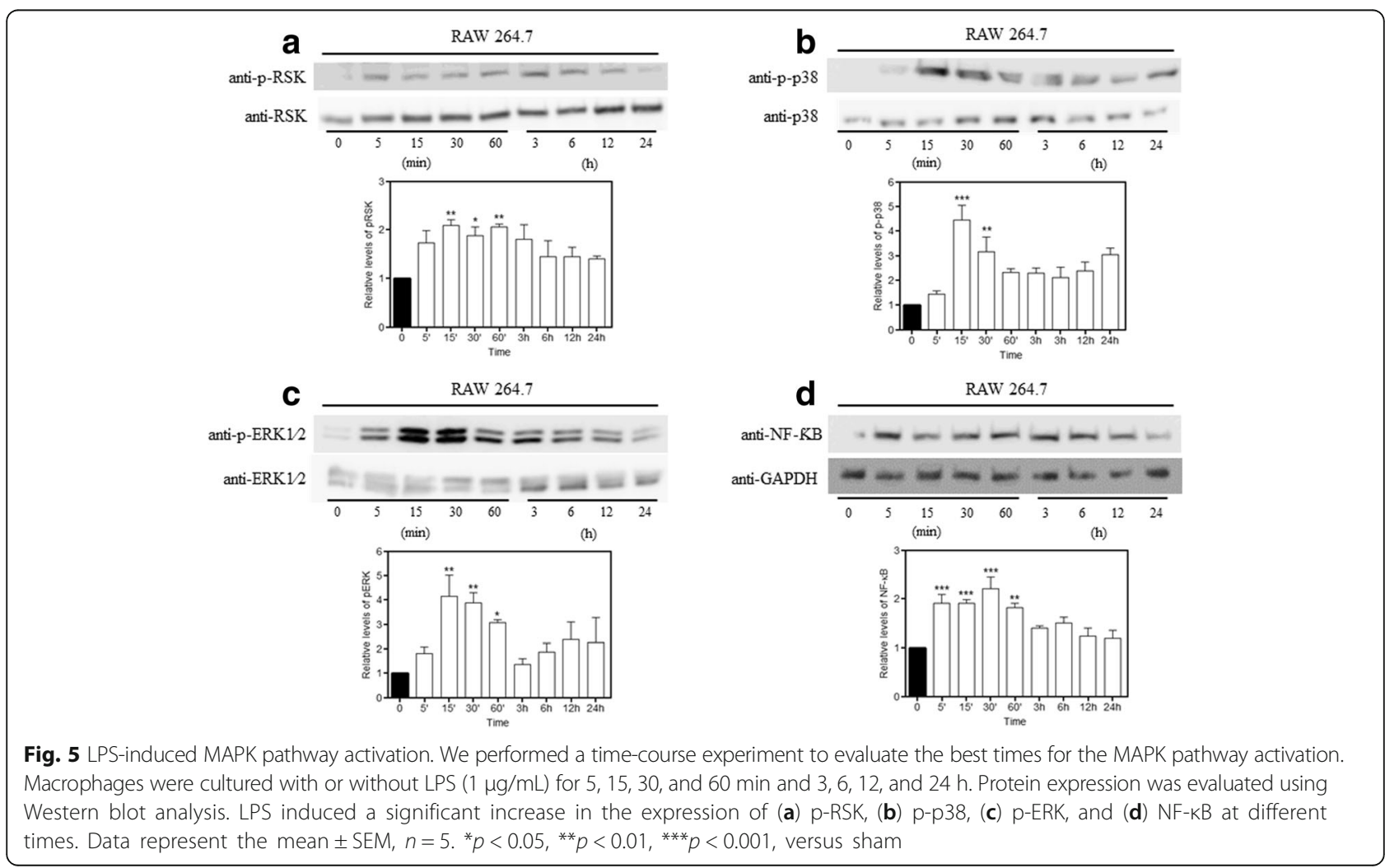



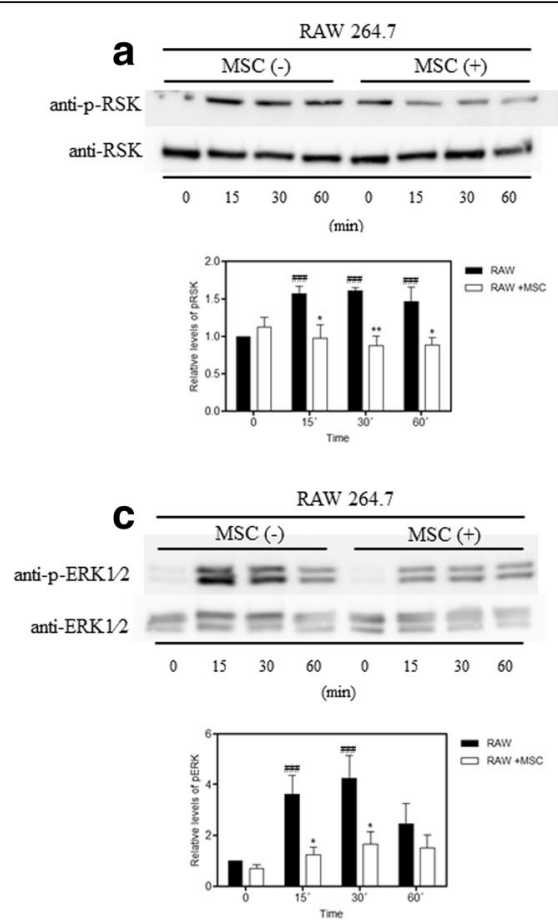
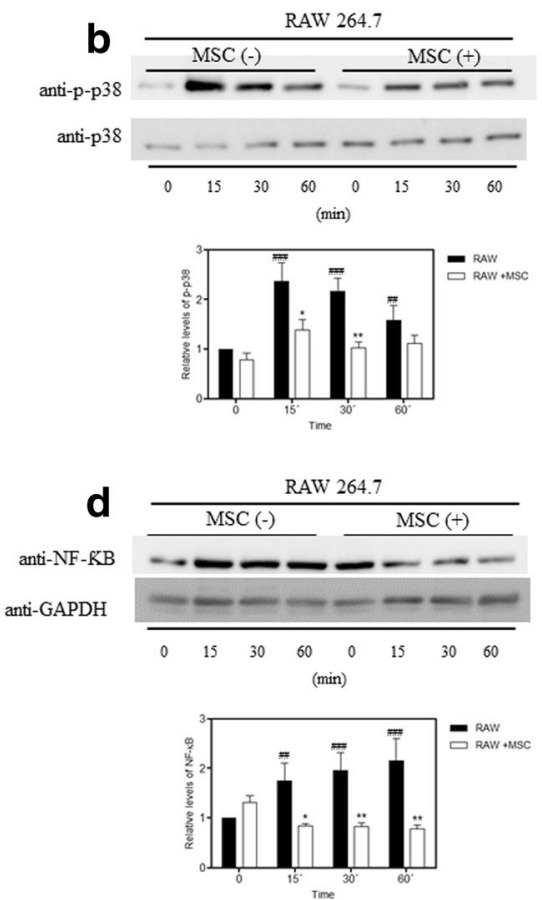

Fig. 6 Co-cultivation with MSCs inhibited LPS-induced phosphorylation of RSK, p38, ERK, and NF-KB expression in macrophages. Macrophages were treated with LPS $(1 \mathrm{\mu g} / \mathrm{mL})$ for 15, 30, and $60 \mathrm{~min}$. The MAPK phosphorylation and NF-KB expression were evaluated by Western blot analysis. a RSK was phosphorylated at 15, 30, and 60 min in response to LPS. The co-culture with mesenchymal stem cells (MSCS) inhibited the activation-associated phosphorylation of RSK at all times. $\mathbf{b}$ p38 phosphorylation was increased in the macrophages treated with LPS after 15, 30, and 60 min, and decreased upon co-cultivation with MSCs at 15 and 30 min. c ERK was phosphorylated after 15 and $30 \mathrm{~min}$ in response to LPS stimulation and this phosphorylation could be inhibited by co-cultivation with MSCs. Blots are representative of at least four separate experiments. d NF-KB expression was increased in the LPS group after 15, 30, and 60 min. This increase was inhibited by MSCs at all times. Data represent the mean \pm SEM, $n=5 .{ }^{\# \#} p<0.01$, ${ }^{\# \#} p<0.001$, versus corresponding untreated controls; ${ }^{*} p<0.05,{ }^{* *} p<0.01$, versus corresponding RAW counterparts

expression of COX-2 and NF-kB over the long term, maintaining the anti-inflammatory effect. Thus, we transfected macrophages with a COX-2 promoterluciferase construct and NF- $\mathrm{kB}$ promoter-luciferase construct separately. According to the analysis of luciferase activity, we observed a significant increase at $24 \mathrm{~h}$ and $48 \mathrm{~h}$ in the group treated with LPS compared with the control group for both COX-2 and NF- $\mathrm{BB}$ promoter activity. This increase was not observed in the group cocultured with MSCs. This result indicates that a possible initial inhibition of phosphorylation of MAPKs by MSCs can lead to inhibition of COX-2 and NF- $\mathrm{kB}$ over the long term, and demonstrates the ongoing anti-inflammatory potential of the MSCs (Fig. 9).

\section{MSCs attenuate LPS-induced IL-1, IL-6, and COX-2, and promote IL-10 expression in macrophages}

The macrophages exposed to LPS for $24 \mathrm{~h}$ with and without co-culture were collected for analysis by quantitative PCR of the mRNA levels of IL-1, IL-6, IL-10, and COX-2. The group treated with LPS had a significant increase in IL-1 at 12, 24, and $48 \mathrm{~h}$. At $48 \mathrm{~h}$, we saw an
IL-6 increase in the sepsis group when compared with the control group. In all cases, co-culture with MSCs was able to significantly reduce this increase (Fig. 10a and b). The levels of the anti-inflammatory cytokine IL10 increase in the groups treated with LPS at 12, 24, and $48 \mathrm{~h}$, and MSCs provoked a significant increase when compared to the group treated with LPS at $24 \mathrm{~h}$ (Fig. 10c). COX-2 levels are increased in the LPS groups at all times, and the MSCs induced a significant reduction at 24 and $48 \mathrm{~h}$ (Fig. 10d).

\section{MAPK p38 and ERK signaling is required for MSC- mediated LPS-induced COX-2 and NF-KB expression in macrophages}

Subsequently, we attempted to prove that the activation of p38 and ERK has an important role in the upregulation of COX-2 and NFKB, and the effects seen on treatment with MSCs possibly occur through this pathway. We measured the expression of $\mathrm{COX}-2$ and $\mathrm{NFKB}$ using a specific inhibitor for p38, SB203580, and another for ERK, U0126. Macrophages previously transfected with the reporter genes were treated with inhibitors and 


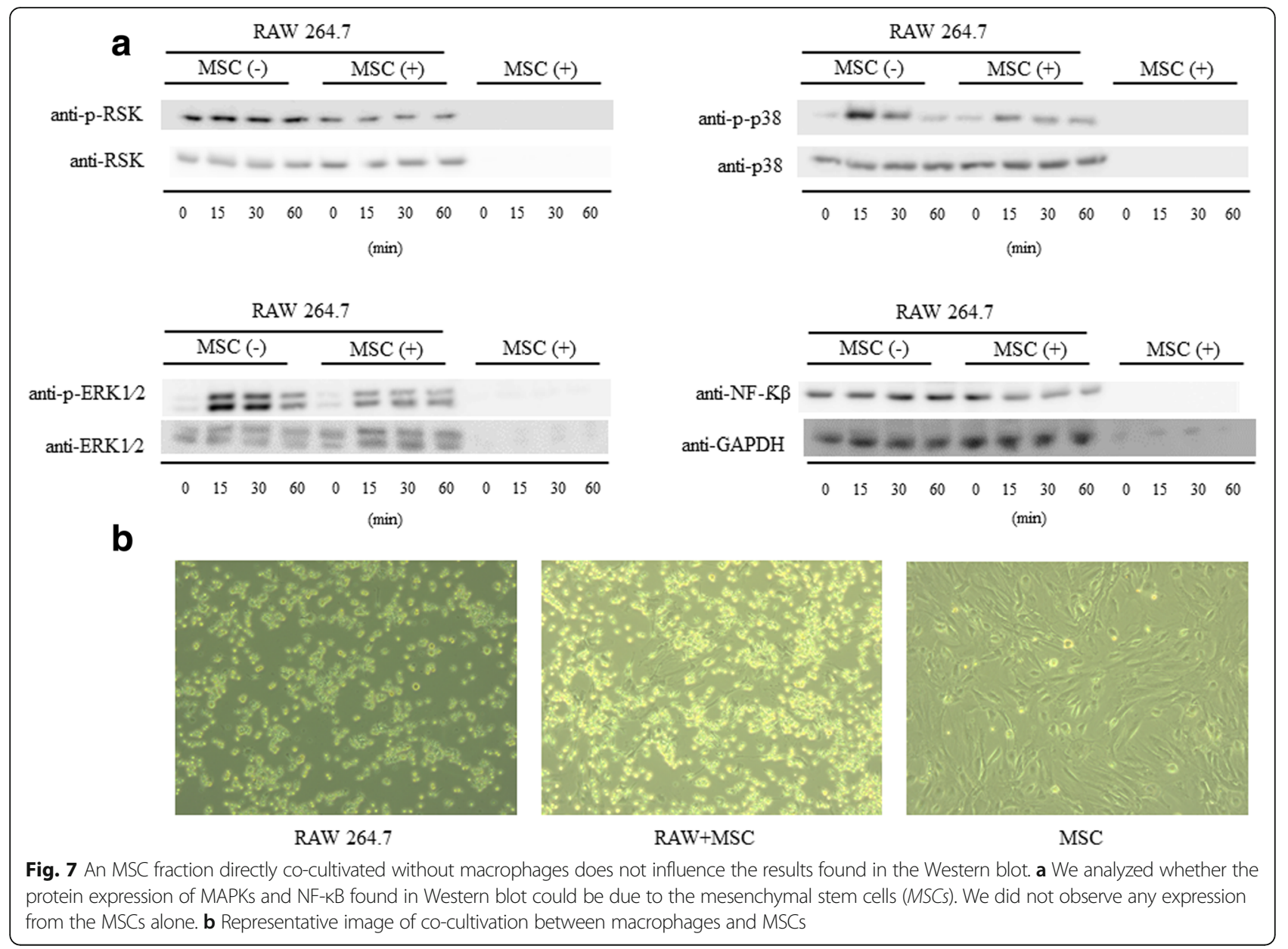

subsequently subjected to LPS for 24 and $48 \mathrm{~h}$. We observed a decrease in the promoter activity of COX-2 and NF- $\mathrm{kB}$ with both inhibitors when compared with the group treated with LPS (Fig. 11). We also measured a group using both inhibitors at the same time to verify any synergistic effect, but none was found. These data suggest that MSCs can decrease COX-2 and NF- $\mathrm{KB}$ expression via the MAPK pathway, p38 and ERK, thereby modulating the inflammation.

\section{Discussion}

In this study we evaluated the effect of MSC therapy in a sepsis model and its possible mechanism of action in pulmonary macrophages. Our study suggests that MSC injection into a sepsis model can improve the inflammation acting via inhibition of the MAPK pathway by generating decreased production of inflammatory mediators.

Sepsis is defined by a generalized inflammation due to a host immune disorder, dysregulation of the clotting cascade, and endothelial dysfunction in response to the invading pathogenic agents [28]. This can progress to septic shock, generating significant dysfunction of multiple organs and potentially resulting in death. Over the past years, several studies have shown the ability of MSCs to attenuate the dysfunction of organs and improve survival in several models of sepsis in animals, suggesting its potential use for treatment of patients with sepsis [11, 16, 29, 30]. MSCs have an intrinsic capacity to migrate to injured tissues, such as the lung, myocardium, brain, liver, and kidney, and can improve the lesion by reducing both local and systemic inflammation via a decrease in the production of proinflammatory cytokines and an increase in production of anti-inflammatory cytokines [31, 32]. In this study, we demonstrated a possible immunomodulatory mechanism of MSCs through this process.

First, we evaluated two models in vivo to identify which would have a greater inflammatory score and which we should use to study the possible mechanism of action of MSCs on the inflammatory response. Our evidence showed that the severe sepsis model developed by our laboratory was a better way, and we thus performed in vivo experiments with this model.

Sepsis causes multiple organ dysfunction, including the cardiovascular system, liver, kidney, and lung. Fifty percent of patients with severe sepsis will develop acute 


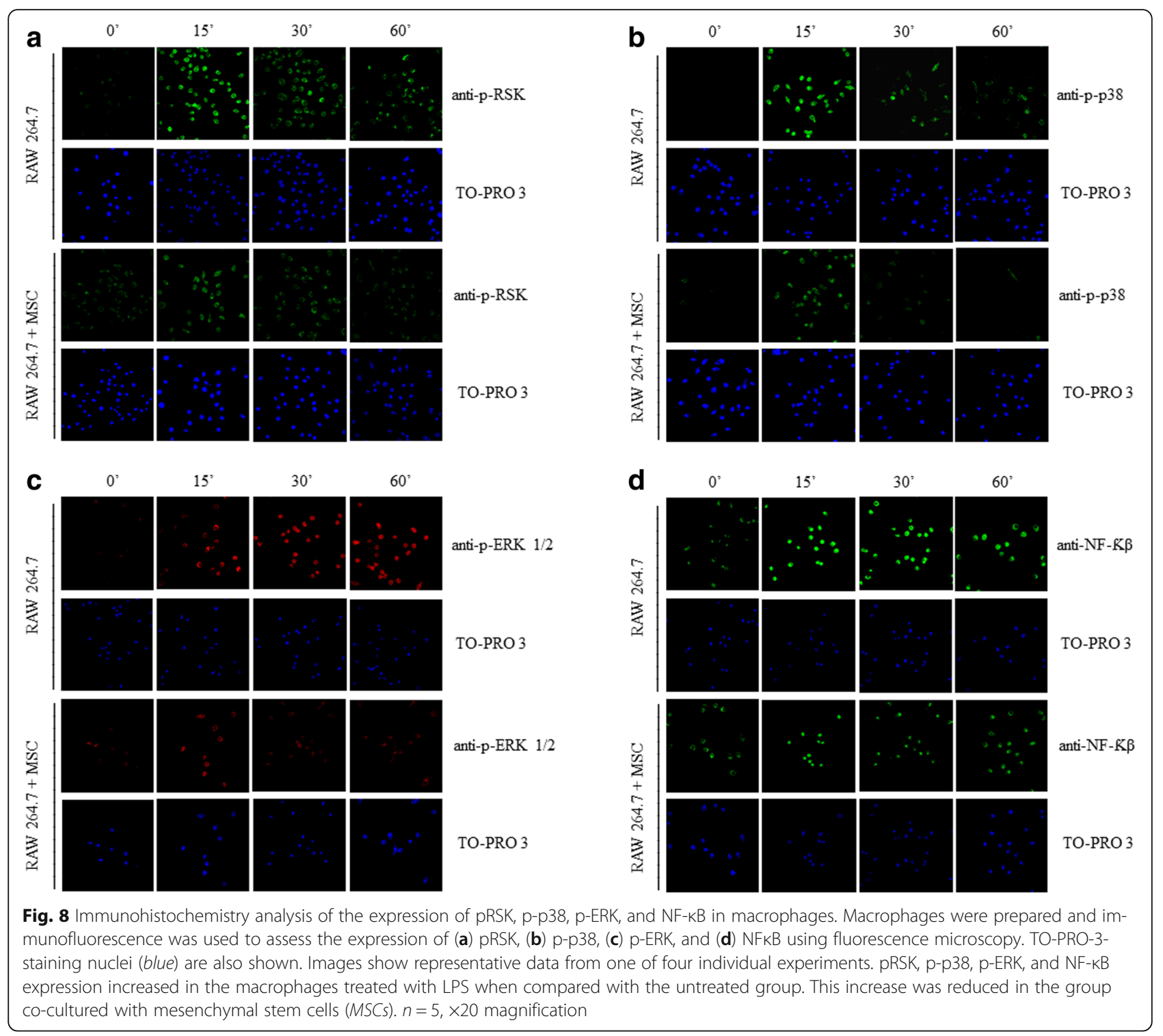

lung injury (ALI) and it is generally considered that damage to the lung is one of the most severe outcomes of sepsis [33]. It was observed that intravenous MSC administration attenuated the score of lung inflammation in our study.

MSCs display some immunosuppressive characteristics that may be quite important in sepsis $[34,35]$. Soluble paracrine signals from MSCs have been shown to downregulate inflammatory cytokine production by macrophages and inhibit neutrophil chemotaxis [36]. When we analyzed the interleukin levels in the serum of the animals, we observed a reduction in inflammatory cytokines IL- 6 and TNF- $\alpha$, and an increase in the production of the anti-inflammatory IL-10, corroborating previous studies [11, 18].

Sepsis is a systemic inflammatory response against bacterial agents. This inflammatory response is characterized by increased inflammatory cytokines TNF- $\alpha$, IL-
1, and IL-6, and anti-inflammatory cytokines, especially IL-10 [37]. Activation of MSCs by pro-inflammatory factors triggers two paracrine negative feedback loops that can reduce inflammation. The first loop involves PGE2, as demonstrated in a study by Németh et al. [18] using a model of sepsis in mice induced by cecal ligation and puncture. In the same study, in in-vitro experiments, MSCs were shown to secrete PGE2 in response to endotoxin (LPS). PGE2 altered the activity of tissue-resident macrophages with a proinflammatory response and stimulated the secretion of an array of anti-inflammatory mediators such as IL-10 and IL-1 receptor antagonist, reducing the systemic effects of sepsis and thus improving survival [18]. However, although these results demonstrate that MSCs reprogram macrophages, how this occurs remained uncertain. 

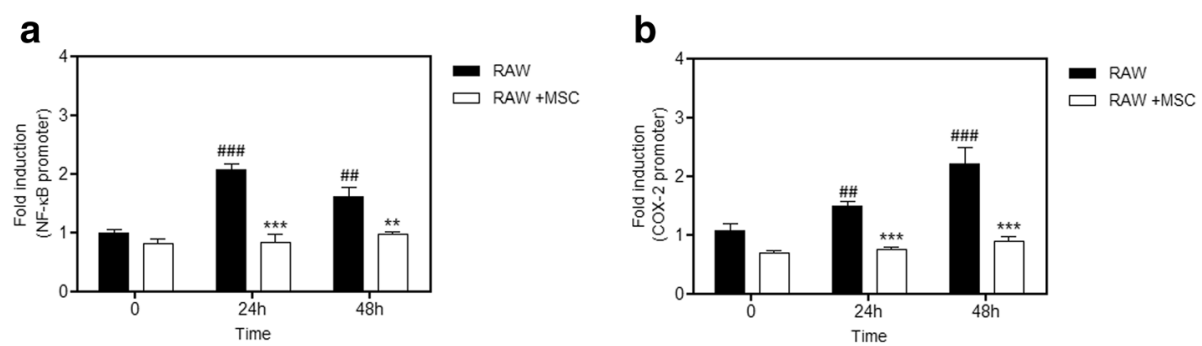

Fig. 9 Induction of COX 2 and NF-KB expression over the long term is reduced by co-cultivation with MSCs. Macrophages were transfected with plasmids as described in the Methods section to evaluate the expression of COX 2 and NF-kB. Macrophages were then co-cultivated or not with mesenchymal stem cells (MSCS), and stimulated with LPS. The induction fold was determined and the luciferase activity was normalized to the $\beta$ galactosidase activity. a NF-KB expression increased in the macrophages treated with LPS when compared with the untreated group at 24 and $48 \mathrm{~h}$. This increase is reduced in the group co-cultured with MSCs. b There was a significant increase in COX-2 protein expression in the group treated with LPS when compared with the untreated group at 24 and $48 \mathrm{~h}$. This increase was inhibited by co-cultivation with MSCs. Data represent the mean $\pm \mathrm{SEM}, n=5 .{ }^{\# \#} p<0.01$, ${ }^{\# \#} p<0.001$, versus corresponding untreated controls; ${ }^{* *} p<0.01,{ }^{* * *} p<0.001$, versus corresponding RAW counterparts

COX-2 is transiently induced after mitogenic or inflammatory stimuli, implicating it in the production of prostaglandins involved in inflammatory responses [38]. Our in vivo results showed that administration of MSCs could decrease COX-2 production following sepsis induction. This led us to seek a possible mechanism of action in vivo in macrophages to justify this inhibition found in the in vivo model.

The pathway that usually regulates COX-2 expression in inflammation involves a family of highly conserved intracellular signaling molecules, the MAPKs [39]. Generally, ERK1/2 responds to mitogens and growth factors that regulate cell proliferation and differentiation, whereas p38 is activated by environmental stresses, such as UV radiation, heat shock, and pro-inflammatory cytokines such as IL-1 and TNF- $\alpha$ [21].

We selected macrophages, which are the predominant immune effector cells, to act as mediators of the inflammatory response and which contribute to both the initiation and resolution of inflammation [40]. First, we evaluated if LPS was effective in activating the MAPK pathway, and we chose short time points since we saw with those a better activation response. When we cocultivated macrophages with MSCs we observed a significant reduction in phosphorylation and that a possible route of action of the MSCs was via the MAPK pathway. This phosphorylation-inhibition mechanism of MSCs on the MAPK pathway is poorly described. Recent studies

\section{a}

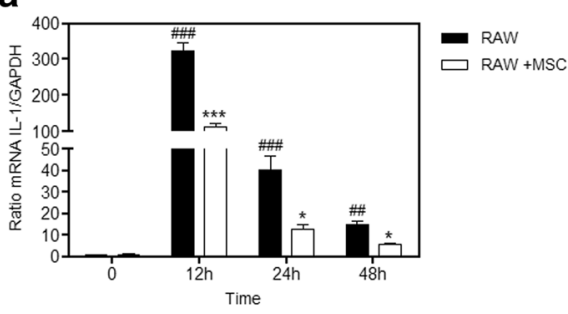

C

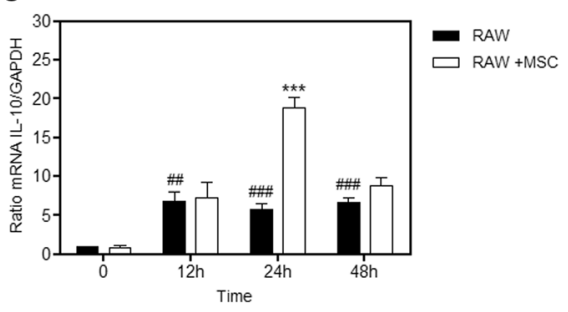

b

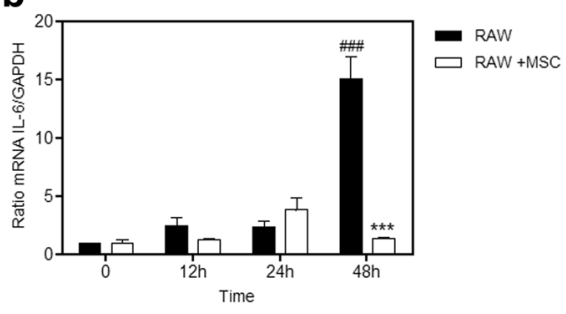

d

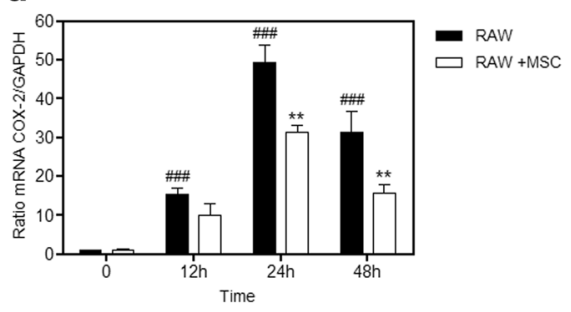

Fig. 10 MSCS attenuated LPS-induced IL-1, COX-2, and IL-6 production, and promoted IL-10 production in macrophages. Macrophages were cultured with or without mesenchymal stem cells (MSCs) with LPS $(1 \mu \mathrm{g} / \mathrm{mL})$ for 12,24 , and $48 \mathrm{~h}$, and were subjected to real-time PCR analysis. LPS significantly increased the (a) interleukin (IL)-1 (12, 24, and 48 h), (b) IL-6 (48 h), and (d) cyclooxygenase-2 (COX-2) (12, 24, and 48 h) when compared with the control group. In the group co-cultivated with MSCS, the mRNA levels of IL-1, IL-6, and COX-2 decreased significantly when compared with the respective LPS group, while (c) the IL-10 mRNA levels increased significantly at $24 \mathrm{~h}$ compared with the LPS group. Data represent the mean $\pm S E M, n=5$. ${ }^{\# \#} p<0.01$, $\# p<0.001$, versus corresponding untreated controls; ${ }^{*} p<0.05,{ }^{* *} p<0.01,{ }^{* * *} p<0.001$, versus corresponding RAW counterparts 

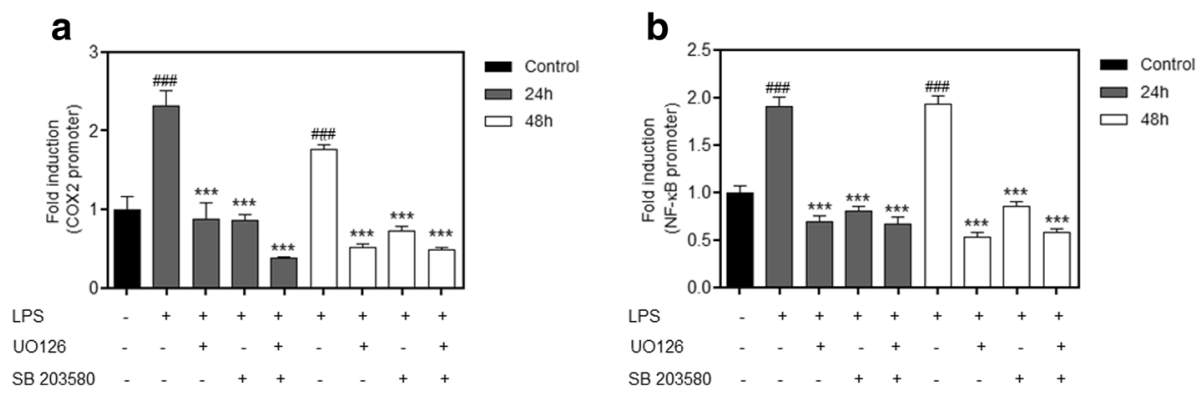

Fig. 11 Inhibition of p38 and ERK has the same effect as that caused by MSCS co-cultured with macrophages stimulated with LPS. Macrophages were transfected with plasmids as described in the Methods section to evaluate the expression of cyclooxygenase-2 (COX-2) and NF-kB. Macrophages were treated with the p38 inhibitor SB203580 and the ERK inhibitor U0126 and stimulated with lipopolysaccharide (LPS). The induction fold was determined and the luciferase activity was normalized to the $\beta$-galactosidase activity. LPS-induced (a) COX-2 and (b) NF-KB upregulation was reduced by the p38 inhibitor (SB203580) and the ERK inhibitor (U0126) at 24 and $48 \mathrm{~h}$. We did not observe any synergistic effect when both inhibitors were administered at the same time. Data represent the mean $\pm \mathrm{SEM}, n=5 .{ }^{\# \# \#} p<0.001$, versus corresponding untreated controls; ${ }^{* * *} p<0.001$, versus the LPS-only group

using a model of cigarette smoke induction showed results similar to the findings in our research [39].

Recent studies have shown that MAPKs can bind to and stimulate kinase targets, translocate to the nucleus, and activate NF- $\mathrm{kB}$ transcription [41]. The ability of MSCs to inhibit the MAPK pathway by co-cultivation is essential for inhibiting the production of NFKB and subsequently the production of other inflammatory mediators. This factor regulated inflammatory cytokines, mainly IL-1, IL-6, and TNF- $\alpha$. As is seen in the in vivo experiments, NF- $\mathrm{kB}$ expression in vitro is also reduced.

Continuing this work, we attempted to investigate if this inhibition profile of $\mathrm{COX}-2$ and $N F-\kappa B$ remained over a longer period of time, and if somehow it could still have an effect on the production and release of proand anti-inflammatory factors derived from macrophages. When we transfected the macrophages with a reporter gene for $\mathrm{COX}-2$ and $\mathrm{NF}-\mathrm{kB}$ we observed that this decrease was maintained in the group co-cultured with MSCs. In addition, mRNA levels of proinflammatory cytokines IL-1 and IL- 6 were higher than in the group co-cultured with MSCs; however, the increase in the anti-inflammatory IL-10 was significantly higher in the co-cultured cells. This shows that the reduction of inflammatory mediators and reprogramming of macrophages caused by MSCs was possibly through the MAPK pathway.

Furthermore, we wanted to show that the action of MSCs was via the MAPK pathway. Thus, we used two specific inhibitors, one for p38 and another for ERK. When we performed an analysis of COX-2 and NF-kB levels, the results showed that both inhibitors were able to inhibit the production of both NF- $\mathrm{kB}$ and COX-2, showing a similar profile to that found when macrophages were co-cultured with MSCs. Altogether, these results suggest that the reduced production of inflammatory mediators caused by MSCs comes from their ability to inhibit the MAPK pathway which would cause a decrease in production of COX-2, NF- $\mathrm{B}$, and other inflammatory mediators during sepsis.

\section{Conclusions}

Our study was able to show that the immunomodulatory effect of MSCs is directly related to their ability to inhibit the activation of MAPKs such as ERK, RSK, or p38, causing a decrease in the production of COX-2 and $\mathrm{NF}-\mathrm{kB}$, and therefore inflammatory cytokines. The way that MSCs act and are able to influence the host response is essential for an understanding in the search for new alternative treatments for sepsis.

\section{Abbreviations}

COX-2: Cyclooxygenase-2; DMEM: Dulbecco's modified Eagle's medium; ERK: Extracellular signal-regulated kinase; FBS: Fetal bovine serum; H\&E: Hematoxylin and eosin; IL: Interleukin; JNK: c-JUN N-terminal kinases; LPS: Lipopolysaccharide; MAPK: Mitogen-activated protein kinase; MSC: Mesenchymal stem cell; NF-kB: Nuclear factor kappa B; PBS: Phosphatebuffered saline; PCR: Polymerase chain reaction; PGE2: Prostaglandin E2; TNF: Tumor necrosis factor

\section{Acknowledgments}

We thank the Scientific and Technological Centers of the Universitat de Barcelona (Campus of Bellvitge) for their technical assistance.

\section{Funding}

This study was supported by a grant from the Conselho Nacional de Desenvolvimento Científico e Tecnológico (CNPq, 400422/2013-1), from the Ministry of Science, Technology and Innovation Education of Brazil.

Availability of data and materials

All data generated and/or analyzed during this study are included in this published article.

\section{Authors' contributions}

LP conceived the work, acquired data, drafted the manuscript, and approved the final version. JLR and JRdO conceived the work, revised the manuscript, and approved the final version. MCR designed the work, revised the manuscript, and approved the final version. FCdM, CL, and AAC acquired data, revised the manuscript, and approved the final version. 


\section{Ethics approval}

The animals were maintained in accordance with the Guiding Principles in the Care and Use of Animals approved by the Council of the American Physiological Society. The experimental protocol was approved by the Ethics Research Committee of Pontifícia Universidade Católica do Rio Grande do Sul (protocol number 14/00403).

\section{Consent for publication}

Not applicable.

\section{Competing interests}

The authors declare that they have no competing interests.

\section{Publisher's Note}

Springer Nature remains neutral with regard to jurisdictional claims in published maps and institutional affiliations.

\section{Author details}

'Laboratório de Pesquisa em Biofísica Celular e Inflamação, Pontifícia Universidade Católica do Rio Grande do Sul (PUCRS), Porto Alegre, Rio Grande do Sul CEP 90619-900, Brazil. ${ }^{2}$ Departament de Ciències Fisiològiques, IDIBELL, Campus de Bellvitge, Universitat de Barcelona, L'Hospitalet de Llobregat, E-08907 Barcelona, Spain. ${ }^{3}$ Laboratory of Pediatric Respirology, Infant Center, Institute of Biomedical Research (IPB), Pontifícia Universidade Católica do Rio Grande do Sul (PUCRS), Porto Alegre, Rio Grande do Sul CEP 90619-900, Brazil.

Received: 22 May 2017 Revised: 12 September 2017 Accepted: 28 November 2017 Published online: 22 December 2017

\section{References}

1. Martin GS, Mannino DM, Eaton S, Moss M. The epidemiology of sepsis in the United States from 1979 through 2000. N Engl J Med. 2003;348:1546.

2. Daviaud F, Grimaldi D, Dechartres A, Charpentier J, Geri G, et al. Timing and causes of death in septic shock. Ann Intensive Care. 2015;5:16.

3. Levy MM, Dellinger RP, Townsend SR, et al. The Surviving Sepsis Campaign: results of an international guideline-based performance improvement program targeting severe sepsis. Intensive Care Med. 2010;36:222.

4. Hotchkiss RS, Tinsley KW, Karl IE. Role of apoptotic cell death in sepsis. Scand J Infect Dis. 2003;35:585.

5. Alcayaga-Miranda F, Cuenca J, Martin A, Contreras L, Figueroa FE, et al. Combination therapy of menstrual derived mesenchymal stem cells and antibiotics ameliorates survival in sepsis. Stem Cell Res Ther. 2015;6:199.

6. Aziz M, Jacob A, Yang W-L, Matsuda A, Wang P. Current trends in inflammatory and immunomodulatory mediators in sepsis. J Leukoc Biol. 2013:93(3):329-42.

7. Martin-Loeches I, Levy MM, Artigas A. Management of severe sepsis: advances, challenges, and current status. Drug Design. Dev Ther. 2015;9: 2079-88.

8. Weil BR, Herrmann JL, Abarbanell AM, Manukyan MC, Poynter JA, Meldrum DR. Intravenous infusion of mesenchymal stem cells is associated with improved myocardial function during endotoxemia. Shock. 2011;36:235-41.

9. Krasnodembskaya A, Samarani G, Song Y, Zhuo H, Su X, et al. Human mesenchymal stem cells reduce mortality and bacteremia in gram-negative sepsis in mice in part by enhancing the phagocytic activity of blood monocytes. Am J Physiol Lung Cell Mol Physiol. 2012;302:L1003-13.

10. Keane C, Jerkic M, Laffey JG. Stem Cell-based Therapies for Sepsis. Anesthesiol. 2017; 127(6):1017-34.

11. Pedrazza L, Lunardelli A, Luft C, Cruz CU, Mesquita FC, et al. Mesenchymal stem cells decrease splenocytes apoptosis in a sepsis experimental model. Inflamm Res. 2014;63:719-28.

12. Hall SR, Tsoyi K, Ith B, Padera RF, Lederer JA, et al. Mesenchymal stromal cells improve survival during sepsis in the absence of heme oxygenase-1: the importance of neutrophils. Stem Cells. 2013:31:397-407.

13. Rani S, Ryan AE, Griffin MD, Ritter T. Mesenchymal stem cell-derived extracellular vesicles: toward cell-free therapeutic applications. Mol Ther. 2015;23(5):812-23.

14. Barry FP, Murphy JM. Mesenchymal stem cells: clinical applications and biological characterization. Int J Biochem Cell Biol. 2004;36:568-84.
15. Monsel A, Zhu Y, Gennai S, Hao Q, Li J, Lee JW. Cell-based therapy for acute organ injury preclinical evidence and ongoing clinical trials using mesenchymal stem cells. Anesthesiology. 2014;121:1099-121.

16. Gonzalez-Rey E, Anderson P, González MA, Rico L, Büscher D, Delgado M. Human adult stem cells derived from adipose tissue protect against experimental colitis and sepsis. Gut. 2009:58:929-39.

17. Mei SH, Haitsma JJ, Dos Santos CC, Deng Y, Lai PF, et al. Mesenchymal stem cells reduce inflammation while enhancing bacterial clearance and improving survival in sepsis. Am J Respir Crit Care Med. 2010;182:1047-57.

18. Németh K, Leelahavanichkul A, Yuen PS, Mayer B, Parmelee A, et al. Bone marrow stromal cells attenuate sepsis via prostaglandin E(2)-dependent reprogramming of host macrophages to increase their interleukin-10 production. Nat Med. 2009:15:42-9.

19. Ricciotti E, FitzGerald GA. Prostaglandins and inflammation. Arterioscler Thromb Vasc Biol. 2011:31(5):986-1000.

20. Kyriakis JM, Avruch J. Mammalian MAPK signal transduction pathways activated by stress and inflammation: a 10-year update. Physiol Rev. 2012;92: 689-737.

21. Cargnello M, Roux PP. Activation and function of the MAPKs and their substrates, the MAPK-activated protein kinases. Microbiol Mol Biol Rev. 2011; 75(1):50-83.

22. Nunes FB, Pires MGS, Filho JCFA, Wachter PH, Oliveira JR. Physiopathological studies in septic rats and the use of fructose-1,6-bisphosphate as cellular protection. Crit Care Med. 2002;30(9):2069-74.

23. Braber S, Henricks PAJ, Nijkamp FP, Kraneveld AD, Folkerts G. Inflammatory changes in the airways of mice caused by cigarette smoke exposure are only partially reversed after smoking cessation. Respir Res. 2010;11:99.

24. Casas-Terradellas E, Tato I, Bartrons R, Ventura F, Rosa JL. ERK and p38 pathways regulate amino acid signalling. Biochim Biophys Acta. 2008;1783: 2241-54.

25. Cubillos-Rojas M, Amair-Pinedo F, Tato I, Bartrons R, Ventura F, et al. Simultaneous electrophoretic analysis of proteins of very high and low molecular mass using tris-acetate polyacrylamide gels. Electrophoresis. 2010; 31:1318-21

26. Bell-Parikh LC, Ide T, Lawson JA, McNamara P, Reilly M, FitzGerald GA. Biosynthesis of 15-deoxy-delta, 12,14-PGJ2 and the ligation of PPAR gamma. J Clin Invest. 2003;112:945-55.

27. Hui Y, Ricciotti E, Crichton I, Yu Z, Wang D, Stubbe J, Wang M, Puré E, FitzGerald GA. Targeted deletions of cyclooxygenase-2 and atherogenesis in mice. Circulation. 2010;121:2654-60.

28. Iskander KN, Osuchowski MF, Stearns-Kurosawa DJ, et al. Sepsis: multiple abnormalities, heterogeneous responses, and evolving understanding. Physiol Rev. 2013;93(3):1247-88.

29. Gupta N, Su X, Popov B, et al. Intrapulmonary delivery of bone marrowderived mesenchymal stem cells improves survival and attenuates endotoxin-induced acute lung injury in mice. J Immunol. 2007;179:1855-63.

30. Xu J, Woods CR, Mora AL, et al. Prevention of endotoxin-induced systemic response by bone marrow-derived mesenchymal stem cells in mice. Am J Physiol Lung Cell Mol Physiol. 2007;293:L131-41.

31. Kean TJ, Lin P, Caplan Al, Dennis JE. MSCs: delivery routes and engraftment, cell-targeting strategies, and immune modulation. Stem Cells Int. 2013;2013: 732742. doi:10.1155/2013/732742

32. Wannemuehler TJ, Manukyan MC, Brewster BD, Rouch J, Poynter JA, Wang $Y$, Meldrum DR. Advances in mesenchymal stem cell research in sepsis. J Surg Res. 2012;173:113-26.

33. Rubenfeld GD, Caldwell E, Peabody E, Weaver J, Martin DP, et al. Incidence and outcomes of acute lung injury. N Engl J Med. 2005;353(16):1685-93.

34. Aggarwal S, Pittenger MF. Human mesenchymal stem cells modulate allogeneic immune cell responses. Blood. 2005;105:1815.

35. Spaggiari GM, Abdelrazik H, Becchetti F, et al. MSCs inhibit monocytederived $D C$ maturation and function by selectively interfering with the generation of immature DCs: central role of MSC-derived prostaglandin E2. Blood. 2009;113:6576.

36. Baraniak PR, McDevitt TC. Stem cell paracrine actions and tissue regeneration. Regen Med. 2010;5(1):121-43.

37. Schulte W, Bernhagen J, Bucala R. Cytokines in sepsis: potent immunoregulators and potential therapeutic targets - an updated view Mediat Inflamm. 2013:2013:165974 doi:10.1155/2013/165974.

38. Maldve RE, Kim Y, Muga SJ, Fischer SM. Prostaglandin $E_{2}$ regulation of cyclooxygenase expression in keratinocytes is mediated via cyclic nucleotide-linked prostaglandin receptors. J Lipid Res. 2000;41:873-81. 
39. Gu W, Song L, Li X-M, Wang D, Guo X-J, Xu W-G. Mesenchymal stem cells alleviate airway inflammation and emphysema in COPD through downregulation of cyclooxygenase-2 via p38 and ERK MAPK pathways. Sci Rep. 2015;5:8733.

40. Peters-Golden M. The alveolar macrophage: the forgotten cell in asthma. Am J Respir Cell Mol Biol. 2004;31:3-7.

41. Sun P, Zhou K, Wang S, Li P, Chen S, et al. Involvement of MAPK/NF-KB signaling in the activation of the cholinergic anti-inflammatory pathway in experimental colitis by chronic vagus nerve stimulation. PLoS One. 2013; 8(8), e69424.

Submit your next manuscript to BioMed Central and we will help you at every step:

- We accept pre-submission inquiries

- Our selector tool helps you to find the most relevant journal

- We provide round the clock customer support

- Convenient online submission

- Thorough peer review

- Inclusion in PubMed and all major indexing services

- Maximum visibility for your research

Submit your manuscript at www.biomedcentral.com/submit
Biomed Central 